\title{
La adscripción del dominio público marítimo-terrestre a las Comunidades Autónomas
}

\author{
María Zambonino Pulito \\ Profesora Asociada de Derecho Administrativo \\ en la Facultad de Derecho de Jerez \\ Universidad de Cádiz
}

Sumario: I. LA ADSCRIPCIÓN DEL DOMINIO PÚBLICO MARITIMO-TERRESTRE COMO TÉCNICA PARA EL EJERCICIO POR LAS COMUNIDADES AUTÓNOMAS DE DETERMINADAS COMPETENCIAS EN EL LITORAL. II. CONCEPTO Y NATURALEZA DE LA ADSCRIPCIÓN. III. DELIMITACIÓN DE LOS SUPUESTOS SUJETOS A ADSCRIPCIÓN, PROBLEMÁTICA COMPETENCIAL QUE PLANTEAN. A. Supuestos sujetos a adscripción. B. Supuestos excluidos de adscripción. IV. SUJETOS. V. OBJETO. VI. LA FORMA DE LA ADSCRIPCIÓN. VII. EFECTOS. VIII. LA REVERSIÓN DE LOS BIENES ADSCRITOS. A. Supuestos que dan lugar a la reversión. B. Procedimientos de reversión. C. Efectos. IX. CONCLUSIONES.

\section{LA ADSCRIPCIÓN DEL DOMINIO PÚBLICO MARÍTIMO- TERRESTRE COMO TÉCNICA PARA EL EJERCICIO POR LAS COMUNIDADES AUTÓNOMAS DE DETERMINADAS COMPETENCIAS EN EL LITORAL}

El sistema de distribución de competencias entre el Estado y las Comunidades Autónomas establecido por la Constitución de 1978 es, sin duda, uno de los aspectos de la norma fundamental cuya delimitación y alcance ha supuesto un mayor esfuerzo por parte de nuestro Tribunal Constitucional y de la propia doctrina científica. La labor llevada a cabo para perfilar dicho sistema se ha visto necesitada de la aclaración de numerosas y variadas cuestiones, entre las cuales ha de destacarse la relativa a la articulación de competencias concurrentes sobre un mismo espacio fisico!

\footnotetext{
1 De esta problemática se ocupó en extenso la que se puede calificar ya, como clásica, STC 77/1984, de 7 de julio. Sin embargo, ha de señalarse que no se trata de una cuestión nueva puesto que ya con anterioridad a la Constitución habian surgido conflictos de articulación de competencias concurrentes entre el Estado y los municipios, conflictos que fueron resueltos por el Tribunal Supremo con argumentaciones similares a las utilizadas en la actualidad por el Tribunal Constitucional.
} 
Esta problemática se hace particularmente intensa cuando el espacio físico en cuestión es el litoral, supuesto que ha despertado el interés de la doctrina muy en especial desde el momento de la publicación de la Ley $22 / 1988$, de 28 de julio, de Costas (en adelante LC), Ley que, partiendo de la titularidad estatal del dominio público marítimo-terrestre, atribuye al Estado intensas potestades en orden a la protección de dicho litoral ${ }^{2}$.

Bien es sabido que la titularidad del dominio público no excluye el ejercicio por las Comunidades Autónomas de las competencias estatutariamente asumidas, mas se hace necesario articular dicho ejercicio con el de las potestades estatales ejercitables sobre el demanio marítimo-terrestre. La forma de entender esta articulación entre potestades y competencias por la LC ha sido objeto de numerosos estudios doctrinales ${ }^{3}$, especialmente en lo atinente a la competencia autonómica de ordenación del territorio y urbanismo ${ }^{4}$ y ha desencadenado las más variadas críticas y, en todo caso, la oposición por parte de varias Comunidades Autónomas que interpusieron los correspondientes recur-

2 En concordancia con el art. $132 \mathrm{CE}$, precepto que establece el carácter de dominio público estatal de la zona maritimo-terrestre, las playas, el mar territorial y los recursos naturales de la zona económica y la plataforma continental. La necesidad de una nueva legislación que, efectivamente, proporcionara las bases para llevar a cabo una adecuada protección de las costas espanfolas era evidente; son ilustrativos los datos que al respecto se aportan en la Exposición de Motivos de la Ley (destrucción de áridos, privatizaciones, urbanismo nocivo, dejación administrativa) que hacian necesaria una toma de actitud de los poderes públicos para evitar una mayor degradación.

3 Sobre el tema, en general, vid. J. BALza Agullera, «Reflexión de carácter constitucional en la Ley de Costas: especial incidencia competencial», CEUMT, «La Ley de Costass, $\mathrm{n}^{\text {}}{ }^{106-107}$ (1988), págs. 89 y ss., también en Jornadas sobre la Ley de Costas, IVAP, Bilbao, 1990, págs. 61 y ss.; M. Bel.ADiez Rojo, «Problemas competenciales sobre la zona maritimo-terrestre y las playas)s en Estudios sobre la Constitución Española. Homenaje al Profesor Eduardo Garcia de Enterria, vol. IV, Ed. Civitas. Madrid, 1991, págs. 3.671 y ss.; J. L. MEILÁN GIL, "Comunidades Autónomas y dominio público maritimo-terrestre. El Proyecto de Ley de Costas», $R D U$ n. ${ }^{\circ} 108$ (1988), págs. 13 y ss.; J. L. MELÁN GL, «La Ley de Costas y las competencias de las Comunidades Autónomas», REGAP n. ${ }^{\circ} 1$ (1992), págs. 37 y ss.; B. NOGUERA DE LA MUELA, "Las competencias estatales y autonómicas en la Ley de Costas de 1988", RVAP, n. 30 (1991), págs. 105 y ss.; M. Zambonino Pulito, Puertos y Costas: Régimen de los puertos deportivos, Tirant lo Blanch, Valencia, 1997, págs. 43 y ss.

4 Vid., al respecto, I. Borrajo InIESTA, «Incidencia de la Ley de Costas en el Derecho Urbanistico», $R A P$ n. ${ }^{\circ} 130$ (1993), págs. 131 y ss.; F. Garcia Agudín, «Incidencia de la Ley de Costas en la gestión y planificación urbanistica", en Dominio público: aguas y costas, Consejo General del Poder Judicial, Madrid, 1993, págs. 187 y ss.; J. L. GonZÁlez-BERENGUER URRUTIA, «La Ley de Costas. Las construcciones futuras", RDU n. 118 (1990), págs. 103 y sS.; A. ORTEGA GARcia, «Implicaciones urbanísticas de la Ley de Costas», RDU, n. ${ }^{\circ} 12$ (1989), págs. 65 y ss.; L. PARejo Alfonso, «Dominio público portuario y ordenación territorial: competencias del Estado y de las Comunidades Autónomas", $R D U \mathrm{n}$. 135 (1993), págs. 13 y ss.; F. Perales MadueÑo, «Implicaciones urbanísticas de la Ley de Costas», XVI Semana de Estudios Superiores de Urbanismo "La Ordenación del Litoral», Centro de Estudios Municipales y de Cooperación Interprovincial, Granada, 1991; A. PÉrez MORENo, «La Ley de Costas y el planeamiento urbanístico», RDU n. 117 (1990), págs. 13 y ss.; M.T. POVEDA DiAz, «La Ley de Costas de 28 de julio de 1988 y la Planificación Territorial y Urbanisticas), $R D U n^{\circ} 115$ (1990), págs. 73 y ss. 
LA ADSCRIPCIÓN DEL DOMINIO PÚBLICO MARITIMO-TERRESTRE...

sos de inconstitucionalidad contra la Ley ${ }^{5}$, fruto de los cuales es la STC 149/1991, de 4 de julio, a la que ha de añadirse la STC 198/1991, de 17 de octubre, que resuelve los recursos de inconstitucionalidad planteados contra el Real Decreto 1471/1989, de 1 de diciembre, por el que se aprueba el Reglamento General para el desarrollo y ejecución de la $\mathrm{LC}^{6}$.

Nos ocuparemos en estas páginas de analizar la técnica que el legislador estatal ha previsto para hacer viable el ejercicio por las Comunidades Autónomas de determinadas competencias cuya gestión conlleva necesariamente la utilización de dominio público marítimo-terrestre. La técnica en cuestión es la denominada adscripción, que se configura en el art. 49.1 LC como la forma de utilización de los bienes de dominio público marítimo-terrestre por las Comunidades Autónomas cuando la finalidad de dicha utilización sea la construcción de nuevos puertos y vías de transporte de titularidad de aquéllas, o la ampliación o modificación de los existentes ?

5 Recursos de inconstitucionalidad 1689/1988, 1708/1988, 1715/1988, 1723/1988, 1728/1988, 1729/1988 y 1740/1988, interpuestos por la Xunta de Galicia, el Consejo de Gobierno de las Islas Baleares, el Gobierno Vasco, el Parlamento de Cataluña, el Consejo de Gobierno de la Diputación Regional de Cantabria, el Consejo Ejecutivo de la Generalidad de Cataluña, el Gobierno de Canarias, el Gobierno valenciano y un grupo de 50 Diputados.

6 En adelante RC. Ha de tenerse en cuenta la modificación llevada a cabo del RC por el Real Decreto $1112 / 1992$, de 18 de septiembre, que ha incorporado la doctrina del Tribunal Constitucional y que pretende adecuar el RC al régimen de competencias estatales y autonómicas en el espacio litoral. Las sentencias relativas a la LC y al RC han sido objeto de diversos comentarios, cfr..., inter alia, J. M. BANDRÉS, «Dominio público maritimo-terrestre y propiedad privada en la Sentencia del Tribunal Constitucional 149/1991, de 4 de julio», REALA n. 258 (1993), págs. 375 y ss.; A. E. DE Asis RoIG, «Policía demanial externa y medio ambiente. Algunas reflexiones sobre la Sentencia del Tribunal Constitucional 149/1991, de 4 de julio", $R D U$ n. ${ }^{\circ} 125$ (1991), págs. 35 y ss.; L. FNARDO SPINOLA, "Coordinación de la actividad de las diferentes Administraciones sobre la costa (Comentaro a la Sentencia del Tribunal Constitucional 149/1991, de 4 de julio)", RAP n. 128 (1992), págs. 235 y ss.; J. L. GonZÁlez-Berenguer UrRuTia, «La sentencia del Tribunal Constitucional 149/1991 relativa a la Ley de Costas», $R D U$ n. 125 (1991), págs. 13 y ss.; M. T. Poveda Diaz, «Estudio sobre las sentencias dictadas por el Tribunal Constitucional en los recursos de inconstitucionalidad planteados contra la Ley 22/1988, de Costas, y el Reglamento General para su desarrollo y ejecución", $R D U$ n. ${ }^{\circ} 125$ (1991), págs. 93 y ss. Volviendo a la cuestión competencial, ha de resaltarse aqui que también las entidades locales cuentan con competencias propias que habrán de desarrollarse en este espacio litoral, tema en relación al cual, encontramos más escasas referencias doctrinales: vid. L. ANGULo ERRAZQUIN, «Las competencias municipales en la Ley 22/88 de Costas, de 28 de julion, Jornadas sobre la Ley de Costas, IVAP, Oñati, 1990, págs. 83 y ss.; R. EstÉvEZ GOYTRE, «Los municipios y la Ley de Costas», RDU n. ${ }^{\circ} 135$ (1993), págs. 67 y ss.

7 El equivalente en Derecho francés, previsto únicamente para la construcción de nuevos puertos, es el acto de "puesta a disposición» del dominio público del Estado con carácter previo a la construcción de dichos puertos por el municipio regulado en el art. R. 613-1 del Código de Puertos Marítimos. La adscripción no es, sin embargo, algo nuevo en nuestro ordenamiento puesto que fue también la técnica prevista en los Reales Decretos de traspasos de bienes y servicios en materia de puertos (Cataluña, Real Decreto 2876/1980, de 12 diciembre, BOE 12 enero 1981; Pais Vasco, Real Decreto 2380/1982, de 14 mayo, BOE 23 y 24 septiembre 1982; Cantabria, Real Decreto 2623/1982, de 24 julio, BOE 19 y 20 octubre 1982; Murcia, Real Decreto 2925/1982, de 12 agosto, BOE 10 y 11 noviembre 1982; Valencia, Real De- 
El mecanismo adscriptorio, hasta el momento poco estudiado ${ }^{8}$, concebido como modo de hacer viable el ejercicio de competencias de titularidad de una Administración distinta a la del espacio fisico sobre el que han de ejercitarse, se nos antoja como especialmente apropiado al fin descrito. Es éste el motivo que hace necesario un análisis en profundidad del régimen de la adscripción que aclare las dudas que la propia legislación de costas ofrece acerca del mismo; un análisis que, por otra parte, ponga de manifiesto todas las posibilidades y resortes que la técnica en cuestión puede ofrecer, y que a nuestro juicio el legislador de 1988 no ha sabido aprovechar, y desde el cual estemos en posición de proponer la extensión de la aplicación de la misma a otros supuestos no previstos en aquella legislación.

Son diversas las cuestiones que no quedan del todo resueltas por la legislación de costas y que presentan una problemática especifica. Tal es el caso de la naturaleza del instituto adscriptorio, $\mathrm{y}$, junto a éste otros aspectos que ciertamente se ven necesitados de cierta aclaración son: el relativo a la delimitación de los supuestos sujetos a adscripción -pues no lo van a estar todos aquellos supuestos en los que las Administraciones autonómicas necesiten utilizar dominio público marítimo-terrestre-; el objeto de la adscripción, que no ha de ser necesariamente toda la superficie que ocupe el puerto o la vía de transporte de titularidad autonómica; la forma de la adscripción, que presenta algunas peculiaridades también dignas de mención; los efectos de la misma, que van a tener una especial incidencia en la gestión del puerto o de la vía de transporte; 0 , finalmente, la reversión del dominio público adscrito, cuyo régimen ofrece ciertas dificultades dignas de ser expuestas.

creto 3059/1982, de 24 julio, BOE 19 y 20 noviembre 1982; Asturias, Real Decreto 3082/1982, de 24 julio, BOE 20 y 22 noviembre 1982; Galicia, Real Decreto 3214/1982, de 24 julio, BOE 27 noviembre 1982; Andalucía, Real Decreto 3137/1983, de 25 agosto, BOE 23 y 24 diciembre 1983; Baleares, Real Decreto 450/1985, de 20 febrero, BOE 10 y 11 abril 1985; Canarias, Real Decreto 2250/1985, de 23 de octubre, BOE n. ${ }^{\circ} 289$, de 3 de diciembre de 1985), articulándose en los mismos a través de un informe emitido por la Administración del Estado, mediante un procedimiento y con un alcance que presentan variaciones sustanciales respecto del régimen vigente y a los que haremos alusión a lo largo de estas páginas.

8 De forma tangencial se alude a ella cuando se estudia la utilización del dominio público marítimo-terrestre, como es el caso del trabajo de Moreno Canoves, Régimen juridico del litoral, Tecnos, Madrid, 1990, págs. 195 y 196; para los puertos deportivos y como un aspecto más del estudio que realiza F. J. JIMÉNEZ DE CISNEROS CID, «El nuevo régimen de los Puertos Deportivos y la Ley de Costas", en Revista de Estudios Territoriales n. ${ }^{\circ} 34$ (1990), págs. 107 y ss., también en Xornadas sobre a lei de Costas organizadas por la Escola Galega de Administración Pública, Santiago de Compostela, noviembre 1991. El único estudio que de forma especifica se ha dedicado a esta figura es el de I. LAZCANO Brotons, "Lla adscripción del dominio público maritimo-terrestre estatal en la normativa y la jurisprudencia constitucional sobre costasn, RVAP n. 33 (1992), págs. 205 y ss.; en este trabajo, sin embargo, se considera que la adscripción tiene una naturaleza juridica radicalmente distinta a la que aquí se propone, $y$, siendo, a nuestro juicio, la cuestión relativa a la naturaleza del instituto adscriptorio la que va a aclarar muchas dudas acerca de su régimen, las consideraciones que aqui hacemos difieren de las alli planteadas. Por nuestra parte, en el trabajo Puertos y costas, op. cit., dedicamos una parte del mismo al estudio de esta figura en las págs. 93 a 116. 


\section{CONCEPTO Y NATURALEZA DE LA ADSCRIPCIÓN}

La adscripción es una de las formas de utilización del dominio público marítimo-terrestre previstas en la legislación de costas junto a las reservas demaniales, a las autorizaciones y a las concesiones. En el art. $49 \mathrm{LC}$ la adscripción se configura como la forma de utilización del demanio marítimo por otra Administración Pública, la autonómica, distinta de la Administración titular de dicho demanio para los fines que en la LC se establecen (construcción, ampliación y modificación de los puertos y vías de transportes de titularidad autonómica). Este uso se va a habilitar a través de la emisión, por parte de la Administración del Estado, de un informe favorable al hilo del procedimiento de aprobación de los proyectos de puertos y vías de transportes autonómicos (art. $49.2^{9}$ ).

La cuestión relativa a la naturaleza de la adscripción es susceptible de encontrar distintas respuestas según la concepción del dominio público que se adopte. Desde la posición según la cual dominio público se identifica con propiedad, tesis ésta sustentada por la doctrina tradicional, LAZCANO BROTONS sostiene que sobre el demanio adscrito, la Comunidad Autonóma ostenta un derecho de superficie. Esta naturaleza de la adscripción, según el citado autor, justificaría la existencia, sobre idéntica parcela, de elementos demaniales con distintas titularidades ${ }^{10}$.

Si se parte, sin embargo, como se hace aquí de la concepción del dominio público como título de intervención que atribuye una serie de potestades a la Administración titular, la justificación de la coexistencia de distintas titularidades sobre un mismo espacio fisico puede encontrarse en el propio concepto de dominio público propuesto, pues la titularidad de dicho demanio consiste, precisamente, en la atribución de las potestades demaniales, potestades que podrá ejercitar, sobre el mismo terreno, cada Administración titular en virtud del título que ostente ${ }^{11}$.

\footnotetext{
9 Ha de diferenciarse la adscripción de la cesión gratuita al Municipio o a la Comunidad Autónoma de temenos desafectados para ser destinados a finalidades de uso o servicio público de la competencia de aquéllos regulada en los arts. 19 LC y $38 \mathrm{RC}$ de bienes. Las diferencias entre una y otra figura han sido sistematizadas por MORENO CANOves, «Régimen juridico del litoral», op. cit., págs. 195 y 196, quien denomina a la segunda (pseudo-adscripción); mas, a nuestro entender, no es posible asimilar la cesión a la adscripción, pues por la propia definición de ésta que se ha propuesto es carácter inherente a la misma que lo que se pone a disposición de otra Administración es el dominio público marítimo-terrestre y no bienes patrimoniales, como es el caso de la cesión.

10 1. Lazcano Brotons, "La adscripción....", op. cit., pág. 224.

1 Sobre la concepción del dominio público como título de intervención atributivo de potestades puede verse el trabajo de Morllo- Velarde Pérez, Dominio puiblico, Trivium, Madrid, 1992, in totum, quien reconstruye el régimen del dominio público desde esta perspectiva y ofrece una clara exposición sobre los origenes de las distintas y encontradas posturas doctrinales al respecto.
} 
Desde esta perspectiva puede afirmarse que, a través de la adscripción, la Administración del Estado dicta un acto administrativo reglado mediante el que se cede el mero ejercicio de ciertas potestades demaniales a otra entidad territorial $(y$ no su titularidad), a la Administración autonómica, la cual se subroga en el ejercicio de dichas potestades en virtud de un título competencial específico (puertos y vías de transporte). Desarrollamos seguidamente estos aspectos.

a) La adscripción es un acto administrativo, carácter que no se desdice por formar la declaración estatal parte del procedimiento de elaboración de otra declaración de voluntad, la autonómica de aprobación del proyecto de construcción, ampliación o modificación del puerto o de la vía de transporte, procedimiento en el que, con el objetivo último de agilizarlo, ha sido integrada por el $\mathrm{RC}^{12}$.

Pensemos que, en puridad, se produce un acto administrativo complejo, el de aprobación del proyecto por la Administración autonómica correspondiente, que se integra por distintas declaraciones, en este caso de voluntad, ambas provenientes de diversas Administraciones Públicas, por lo que estaríamos ante un supuesto de lo que la doctrina ha venido a denominar complejidad externa ${ }^{13}$. Una de las declaraciones de voluntad es la constituida por el informe estatal relativo a la adscripción, la otra, la declaración que tiene por objeto la aprobación del proyecto referente al puerto o a la vía de transporte, corresponderá emitirla a la Administración autonómica ${ }^{14}$.

La declaración de la Administración estatal es, pues, una declaración de voluntad perfecta en sí misma, a través de la cual y de forma unilateral, la Administración del Estado decide si adscribe o no los terrenos en cuestión a la Comunidad Autónoma ${ }^{15}$. Y como tal declaración de voluntad es residenciable

12 En este sentido STC 149/1991, de 4 de julio. Ésta era también la forma por la que se adscribia el dominio público maritimo-terrestre prevista por los Decretos de traspasos de servicios en materia de puertos.

13 Es el caso de todos los dictámenes vinculantes. Al respecto, manifiesta J. M. Boquera OLIVER, Es. tudios sobre el acto administrativo, Civitas, Madrid, 1988, pág. 187, «...el dictamen vinculante es, en su esencia, una declaración de voluntad y no un parecer o juicion.

14 Se trataria, pues, de actos independientes que se integran de forma sucesiva en el mismo procedimiento, actos a los que hace referencia el art. 64.2 de la Ley 30/1992, de 26 de noviembre, de Régimen Jurídico de las Administraciones Públicas y del Procedimiento Administrativo Común (LPAC), cuando regula la denominada «transmisibilidad» de la nulidad o anulabilidad, aunque por el contenido del precepto el término más apropiado seria el de uintransmisibilidad», por cuanto dispone que la nulidad o anulabilidad de un acto no implicará la de los sucesivos en el procedimiento que sean independientes del primero.

15 Como se verá posteriormente, la exteriorización de esta declaración tendrá lugar mediante el levantamiento del acta de adscripción, cuyo objeto no es otro que el de dejar constancia de cuál es el dominio público que se adscribe, sin que el hecho de que haya de suscribirse por representantes de ambas Administraciones tenga mayores consecuencias que las que se acaban de exponer en el sentido de que 
LA ADSCRIPCIÓN DEL DOMINIO PÚBLICO MARITIMO-TERRESTRE...

en la jurisdicción contencioso-administrativa, puesto que dentro del procedimiento de aprobación del proyecto constituiría un acto de trámite que resuelve el fondo del asunto en su caso ${ }^{16}$.

b) El contenido de la declaración de voluntad de la Administración estatal, el contenido, en definitiva del acto de adscripción, como de forma expresa establece el art. 49.2 LC, va a venir referido a la delimitación del demanio susceptible de adscripción, los usos previstos, y las medidas necesarias para la protección del dominio público. El informe estatal, por tanto, habrá de versar sobre todos, y únicamente sobre estos aspectos, por cuanto el exceso podría suponer una conculcación del sistema de competencias, de forma que se interfirieran las autonómicas en materia de puertos y vías de transportes.

Así lo ha entendido el Tribunal Constitucional, quien en la STC 149/1991, de 4 de julio, ha justificado y delimitado el alcance del informe estatal:

1. La justificación del informe estatal viene determinada por la legitimidad de un cauce que permite conocer a la Administración del Estado a tiempo si las obras proyectadas por una Comunidad Autónoma pueden llegar a producir una alteración importante del dominio, o influyen sobre las costas y afectan a su regresión o distorsionan la dinámica litoral. Ahora bien, salvaguardados estos legítimos intereses demaniales, queda agotada la intervención del Estado, cuya Administración no está autorizada por este precepto para inmiscuirse en el ejercicio de la competencia autonómica.

2. Debido al fundamento exclusivamente demanial de la adscripción, el alcance de la intervención estatal para posibilitarla ha de ceñirse a preservar la integridad física y jurídica del demanio marítimo-terrestre. Ello, no obstante, no impide que la Administración del Estado, por razones de economía procedimental y de lealtad y colaboración mutuas, aproveche el informe bajo el cual la Ley instrumenta su intervención para formular aquellas observaciones, críticas, o sugerencias que fluyan del ejercicio de alguna de sus competencias sectoriales, tales como iluminación de costas, marina mercante, sanidad exterior, etc. ${ }^{17}$

\footnotetext{
otorgue naturaleza convencional al acto de adscripción. Es la Administración del Estado, y únicamente ésta, la que, en atención a los criterios establecidos en la legislación de costas, decide sobre la procedencia de adscribir o no.

16 Art. 37 LJCA. Vid. en este sentido, J. A. Garcia-Trevijano Fos, Los actos administrativos, Civitas, Madrid, 1986, págs. 321 y 322.

17 Vid. arts. 106.3 RC, 146.6 RC, y las prescripciones introducidas por las siguientes normas: Ley 8/1975, de 12 de marzo, de Zonas de Interés para la Defensa Nacional; Real Decreto 689/1978, de 10 de febrero,
} 
c) Mediante la adscripción la Administración autonómica se subroga en el ejercicio de ciertas potestades estatales; es necesario, por tanto, proceder a la concreción de dichas potestades. En este sentido el propio art. 49.1 LC expresamente dispone que a la Comunidad Autónoma corresponderá la utilización y gestión del dominio público adscrito. El problema en este punto se centra en determinar si la Comunidad Autónoma se subroga en el ejercicio de todas las potestades demaniales 0 , por el contrario, quedan algunas para que las ejercite la Administración del Estado. En definitiva, se trata de determinar qué es lo que hay que entender por «utilización y gestión» del dominio público, tarea para la cual habrá de examinarse cuáles son las potestades que comporta la titularidad del dominio público, potestades que, según la doctrina tradicional, pueden ser clasificadas en dos categorías: potestades de uso y aprovechamiento, y potestades de defensa y conservación ${ }^{18}$.

El contenido de la expresión empleada por la LC, la «utilización y gestión», se correspondería con las potestades de uso y aprovechamiento; éstas van a ser, por tanto, las potestades que, mediante la adscripción, podrán ser ejercitadas por las Comunidades Autónomas en el dominio público marítimo-terrestre. Consecuentemente, interpretando el art. 49.1 LC sensu contrario, corresponderá al Estado el ejercicio de las restantes potestades derivadas de la titularidad demanial, esto es, las potestades de defensa y conservación (deslinde, recuperación de oficio, publicidad posesoria, potestad sancionadora), debiendo articularse tal ejercicio con las competencias autonómicas sobre puertos y vías de transporte.

d) La subrogación por parte de las Comunidades Autónomas en el ejercicio de las potestades demaniales no va a suponer, sin embargo, la traslación de la titularidad sobre las mismas, conservando, en cualquier caso, la Administración del Estado dicha titularidad. De ello es exponente el contenido del art. 49 LC: «la porción de dominio público adscrita conservará tal calificación jurídica» (la de bienes de dominio público marítimo-terrestre). Al conservar los bienes dicha calificación, la titularidad de los mismos seguirá correspondiendo a la Administración del Estado, de ahí se sigue que, si el dominio público es un título atributivo de potestades, también conservará dicha Administración la titularidad de las potestades a ejercitar sobre los mencionados bienes.

aprueba el Reglamento para su ejecución; Real Decreto 969/1994, de 13 de mayo, por el que se aprueba el Reglamento para el ejercicio de la potestad sancionadora en materias de Zonas de Interés para la Defensa nacional, Reclutamiento para el Servicio Militar y Seguridad Social de las Fuerzas Armadas; Orden de 28 de abril de 1994, por la que se adscriben a las Autoridades Portuarias las instalaciones de iluminación de costas y señalización maritima incluidas en su ámbito geográfico y se determinan las zonas de inspección del funcionamiento de las señales maritimas. 
e) En otro orden de ideas, y desde la perspectiva del grado de vinculación de la Administración al dictar el acto administrativo complejo por el que tiene lugar la adscripción, es de resaltar el carácter reglado de dicho acto. Así se desprende del tenor de la STC 149/1991, de 4 de julio, al afirmar en ella el Tribunal Constitucional que lo contrario, es decir, la consideración del carácter discrecional del acto de adscripción, supondría la posibilidad de que la Administración estatal limitara las competencias autonómicas en materia de puertos y vías de transportes. Este carácter reglado del acto de adscripción va a suponer que, siempre que el proyecto presentado por la Comunidad Autónoma interesada cumpla las condiciones que la legislación de costas establece, la Administración del Estado habrá de emitir informe favorable $\mathrm{y}$, consecuentemente, adscribir la porción de dominio público marítimo-terrestre.

Las condiciones aludidas que establece la legislación de costas en relación al proyecto de puerto o vía de transporte de titularidad autonómica son: que la superficie de terreno cuya adscripción se solicita se limite a la ocupada por la zona de servicio del puerto o por la vía de transporte (art. 103.2 RC); que los usos previstos sean conformes a los permitidos por la legislación de costas, y limitados a los puertos y vías de transportes (art. 49.2 LC); que se establezcan en el proyecto las medidas necesarias para la protección del dominio público (art. $49.2 \mathrm{LC}){ }^{\text {T9 }}$.

Cumplimentadas en el proyecto estas condiciones, y tras la verificación de las mismas por parte de la Administración estatal, ésta ha de adscribir el dominio público marítimo-terrestre necesario para el ejercicio de las competencias autonómicas. Esta afirmación no se desdice por la introducción de conceptos jurídicos indeterminados en el citado art. $20 \mathrm{LC}$, tales como defensa de su integridad, preservación de sus caracteristicas y elementos naturales, prevención de las perjudiciales consecuencias de obras e instalaciones, ya que estos conceptos podrán ser precisados en el momento de su aplicación, admitiendo una única solución justa en cada caso concreto, solución, por otra parte, susceptible de control jurisdiccional ${ }^{20}$.

\section{DELIMITACIÓN DE LOS SUPUESTOS SUJETOS A ADSCRIPCIÓN, PROBLEMÁTICA COMPETENCIAL QUE PLANTEAN}

La adscripción así considerada se configura en la LC como la técnica a través de la cual las Comunidades Autónomas pueden utilizar el dominio público

19 El alcance de esta última condición va a ser precisado en el art. $20 \mathrm{LC}$, según el cual «la protección del dominio público marítimo-terrestre comprende la defensa de su integridad y de los fines de uso general a que está destinado; la preservación de sus caracteristicas y elementos naturales y la prevención de las perjudiciales consecuencias de obras e instalaciones, en los términos de la presente Ley».

20

Pueden verse, entre otras, las SSTS de 12 de diciembre de 1979 y 13 de julio de 1984. 
marítimo-terrestre para el ejercicio de sus competencias. Sin embargo, esta afirmación ha de ser matizada por cuanto la técnica adscriptoria ni va a servir para articular el ejercicio de todas las competencias autonómicas a ejercitar sobre el litoral, ni comprende todas las actuaciones que una Comunidad Autónoma, en virtud de las competencias para cuyo ejercicio haya de adscribirse demanio marítimo, pueda ejercitar sobre dicho demanio. Las competencias para cuyo ejercicio se concibe la adscripción son las relativas a puertos y vías de transporte, siendo necesaria la adscripción, únicamente, para los supuestos de construcción, modificación y ampliación de los mismos.

A continuación examinaremos qué competencias y qué actuaciones, en virtud de aquéllas, se inscriben dentro del instituto adscriptorio, exponiendo y analizando la virtualidad de los criterios utilizados por el legislador para realizar tal discriminación. Para completar la delimitación anunciada se expondrán los supuestos excluidos de adscripción, indicándose cuál es la fórmula por la que en estos casos se ha optado para articular la utilización de la Comunidad Autónoma del demanio marítimo-terrestre en el ejercicio de sus competencias propias.

\section{A. Supuestos sujetos a adscripción}

En base al art. 49.1 LC anteriormente transcrito, quedan sujetas a adscripción tanto la construcción, como la ampliación, como, en su caso, la modificación de los puertos y vías de transporte de competencia autonómica. Dos cuestiones surgen en este punto: delimitar cuáles son los puertos y vías de transporte de competencia autonómica, para, una vez conocidos estos extremos, determinar el alcance de las actuaciones que, sobre estos bienes, han de sujetarse a adscripción para que puedan ser llevadas a cabo.

a) La delimitación de cuáles sean los puertos y vías de transporte de competencia autonómica parte del análisis de la distribución competencial en dichas materias.

En relación a la de puertos ${ }^{21}$, el Estado ostenta competencia exclusiva en cuanto a los de interés general (art. 149.1.20 CE), variando las competencias auto-

21 Sobre la problemática competencial en materia de puertos pueden verse, L. M. ANGULo ERrAZQUIN, «Las competencias de la Administración municipal en las zonas portuarias y su problemática», RVAP, n. 23 (1989), págs. 7 y ss.; P. Escribano Collado, «Las competencias de las Comunidades Autónomas en materia de puertos", RAP, 100-102, vol. III (1983), págs. 2.315 y ss., tambièn en Organización territorial del Estado, T. II, Instituto de Estudios Fiscales, Madrid, 1984, págs. 925 y ss.; T. R. FernáNDEZ RodRiguez, «Regulación urbanistica de los tertenos e instalaciones portuarias», en el volumen colectivo, Comentarios a la nueva Ley de Puertos, Jornadas de Estudio, Consor- 
LA ADSCRIPCIÓN DEL DOMINIO PÜBLICO MARITIMO-TERRESTRE.

nómicas según nos refiramos a Comunidades Autónomas de las denominadas de autonomía plena o a Comunidades Autónomas de autonomía diferida. Las primeras alcanzan un grado mayor de competencias según la asunción que de las mismas se llevó a cabo en sus Estatutos.

En este sentido todas las Comunidades Autónomas de autonomía plena, o de primer grado, constituidas en base al art. 151 (Andalucía) y a la disposición transitoria 2. (Cataluña, País Vasco y Galicia), asumieron la competencia exclusiva sobre los puertos enumerados por el 148.1 .6 (puertos de refugio, puertos y aeropuertos deportivos y, en general, los que no desarrollen actividades comerciales) y los que no sean de interés general del Estado. Además, algunas (Galicia y Andalucía) asumieron competencias de desarrollo legislativo y ejecución de la legislación del Estado sobre puertos pesqueros; otras (País Vasco, Cataluña y Andalucía) asumen competencias de ejecución de la legislación del Estado sobre puertos de interés general ${ }^{22}$.

Las Comunidades Autónomas de autonomía diferida, o de segundo grado, asumieron competencias exclusivas sobre los puertos enumerados en el art. 148.1.6, equiparándose no obstante Valencia a las Comunidades Autónomas de autonomía plena ${ }^{23}$.

cio de la Zona Franca de Vigo, 1993, págs. 77 y ss.; F.J. JiMÉnEZ DE CISNEROS CID, «El nuevo régimen de los Puertos Deportivos..., op. cit., págs. 107 y ss.; F.J. JIMÉNEZ DE CISNERos CID, «La ordenación juridica de la zona de servicio de los puertos de interés general», RVAP n. ${ }^{\circ} 36$ (1993), págs. 167 y ss. y RDU n. 134 (1993), págs. 117 y ss.; M. Zambonino Pulrto, Puertos y Costas.., op. cit., págs. 116 y ss. Exclusivamente en relación a los puertos, la Ley 27/1992, de 24 de noviembre, de Puertos del Estado y de la Marina Mercante, dispone, en su art. 16 que (los espacios de dominio público maritimo-terrestre que sean necesarios para el ejercicio por las Comunidades Autónomas de las competencias que les correspondan estatutariamente en materia de puertos deberan ser objeto de adscripción por la Administración del Estado».

22 Arts. 10.32 y 12.8 EA País Vasco; 9.15 y 11.8 EA Cataluña; 27.9 y 28.6 EA Galicia; $13.11,17.7$ y 15.1.6 EA Andalucía). Constituyendo, junto a Galicia, uno de los dos únicos casos en los que se han asumido competencias de desarrollo legislativo y ejecución sobre los puertos pesqueros, la Comunidad Autónoma de Andalucia es la Comunidad qué más competencias asumió en su Estatuto en relación a los puertos. Por otra parte y, respecto de la asunción de competencias de ejecución en relación a los puertos de interés general, es necesario señalar que el único caso de traspaso en este sentido fue el realizado en relación al entonces calificado como de interés general puerto de Badalona.

23 Arts. 10.1.e EA Asturias; 22.6 EA Cantabria; 10.1.e) EA Murcia; 29.16 EA Canarias; 10.5 EA Baleares; 31.15 y 33.7 EA Valencia. En este último caso el Estado transfirió, por la via ofrecida por el art. 150.2 CE, a la Comunidad valenciana las competencias que figuraban en su Estatuto y que excedian del marco del art. $148 \mathrm{CE}$ mediante la Ley Orgánica 12/1982, de 10 de agosto de 1982, Ley que ha sido recientemente derogada por la Ley Orgánica 12/1994, de 24 de marzo, incorporándose las competencias atribuidas por el Estatuto por la Ley Orgánica 5/1994, de 24 de marzo, sobre reforma del Estatuto de Autonomia de la Comunidad Valenciana. Las Leyes Orgánicas de reforma de los Estatutos de las restantes Comunidades Autónomas que accedieron a la Autonomia por la vía del art. 143 de la Constitución que anteriormente se citaron, no han incluido la competencia sobre puertos que no sean de interés general, pues tampoco se incluian en los correspondientes artículos estatutarios que relacionaban las competencias denomina- 
Finalmente, y en materia de vías de transporte, las Comunidades Autónomas pudieron asumir competencias sobre los ferrocarriles y carreteras cuyo itinerario se desarrolle íntegramente dentro de su territorio (art. 148.1.5 CE), hasta el límite, para las de primer grado, establecido en el art. 149.1.21 (aquellos cuyo itinerario transcurra por el territorio de más de una Comunidad Autónoma), asumiéndose, en los distintos Estatutos de Autonomía de las Comunidades Autónomas costeras, competencias en materia de ferrocarriles, carreteras y caminos con itinerario dentro de la respectiva Comunidad Autónoma ${ }^{24}$.

Son las descritas las competencias para cuyo ejercicio habrá de solicitarse, por parte de la Comunidad Autónoma implicada, la adscripción del dominio público marítimo-terrestre necesario para dicho ejercicio. Pero como adelantábamos anteriormente, incluso dentro de estos supuestos, son limitadas las actuaciones que quedan sometidas a la técnica adscriptoria.

b) Dichas actuaciones se contemplan en el art. $49 \mathrm{LC}$, y son la construcción, ampliación y modificación de puertos y vías de transporte de competencia autonómica. En una primera aproximación, y, según la filosofia de la técnica que nos ocupa, el criterio para delimitarlas parece ser el de que dichas actividades supongan un nuevo «consumo» de litoral, una utilización del dominio público marítimo-terrestre.

Este criterio parece válido en los supuestos de construcción y ampliación de puertos deportivos, supuestos que no ofrecen dudas respecto de la obligación de adscribir el demanio marítimo. Sin embargo, en el caso de simple modificación, no está tan clara la presencia de dicho criterio. La casuística puede ser variada, si bien es posible centrarla en dos posibilidades: modificación que implique utilización de demanio marítimo, y modificación dentro del puerto o

das diferidas y que podrian ser objeto de ampliación (Ley Orgánica 1/1994, de 24 de marzo, de reforma de los arts. 10, 11, 12, 13 y 18 de la Ley Orgánica 7/1981, de 30 de diciembre, del Estatuto de Autonomía para Asturias; Ley Orgánica 2/1994, de 24 de marzo, sobre reforma del Estatuto de Autonomia para Cantabria; Ley Orgánica 4/1994, de 24 de marzo, sobre reforma del Estatuto de Autonomía de la Región de Murcia; Ley Orgánica 9/1994, de 24 de marzo, de reforma del Estatuto de Autonomia para las Islas Baleares, todas en el BOE n. ${ }^{\circ} 72$, de 25 de marzo).

24 Arts. 10.32 y 34 EA Pais Vasco; 9.14 y 15 EA Cataluña; 28.6 EA Galicia; 13.10 EA Andalucia; 31.14 y 15 EA Valencia, 10.1.d EA Asturias; 10.5 EA Baleares; 29.13 EA Canarias; 22.5 EA Cantabria; 10.1.d EA Murcia. En los preceptos citados se alude también al transporte por ferrocarril, carretera, maritimo, fluvial, por cable, etc., lo que lleva a I. LAZCANo Brotons, «La adscripción...», op. cit., pág. 214, a afirmar que también en estos supuestos es aplicable la adscripción. Sin embargo, ha de hacerse notar que, a pesar de que hubiera sido deseable su extensión a otros supuestos, las vias de transporte, y el transporte constituyen dos materias diferenciadas sobre las que las Comunidades Autónomas han asumido competencias en el marco del art. $148 \mathrm{CE}$, y es únicamente a la primera a la que hace referencia expresa el art. 49 LC, y por tanto, exclusivamente para la gestión de esta competencia autonómica podrá ser utilizada la técnica adscriptoria. 
de la vía de transporte existente, y que, por tanto, no conlleve el uso de más demanio marítimo del que ya estaba adscrito. En el primer caso es indudable la necesidad de adscribir los terrenos necesarios para la modificación. En el segundo de los supuestos enunciados, en la medida en que no se "consume» más litoral del anteriormente adscrito, surgen dudas acerca de la viabilidad de la utilización de la adscripción. Sin embargo, teniendo en cuenta el contenido del acto adscriptorio, el cual, como anteriormente expusimos, debe centrarse en la protección del litoral, y como quiera que la modificación del puerto puede implicar efectos perjudiciales para el mismo, el Tribunal Constitucional ha justificado la intervención de la Administración titular del dominio público afectado (STC 149/1991).

c) La adscripción es necesaria para construir, ampliar o modificar puertos o vías de transporte de competencia autonómica cualquiera que sea o vaya a ser su forma de gestión. Esta apreciación viene al caso por cuanto, si bien en la LC nada se determinaba al respecto, el art. 103.2 RC, en su antigua redacción establecía regímenes distintos para la gestión directa y para la gestión indirecta. Disponía así el precepto citado que la adscripción sólo se daría en los supuestos de gestión directa del puerto por la Comunidad Autónoma, mientras que en los casos de gestión indirecta, el peticionario debería solicitar la concesión de ocupación de bienes de dominio público marítimo-terrestre a la Administración del Estado (art. $64 \mathrm{LC}$ ), ello sin perjuicio de las que fueran exigibles por la Comunidad Autónoma en virtud de sus competencias en materia de puertos o vías de transporte.

La anterior disposición fue objeto de severas críticas doctrinales ${ }^{25} \mathrm{y}$, lo que desde el punto de vista práctico tuvo mayores consecuencias, anulada por el Tribunal Constitucional, en su STC 198/1991, con base a la siguiente argumentación:

«La crítica que efectúan unánimemente las cuatro Comunidades Autónomas que han planteado el conflicto contra el apartado 2 del art. 103 se encuentra evidentemente fundada, porque este precepto restringe drásticamente el margen que el art. 49 LC deja para la actuación de las Comunidades Autónomas en ejercicio de sus competencias sobre vías de transporte y, sobre todo, sobre puertos. No se trata de dilucidar, como presupone el Abogado del Estado, si el sistema de dualidad concesional (concesión demanial otorgada por el Estado, y concesión portuaria otorgada por la Autonomía) es o no tan respetuoso con el orden constitucional de competencias como el sistema de concesión autonómica única, previo informe con virtualidad adscriptoria por parte de la Administración del Estado. La opción entre estos dos sistemas para acomodar o integrar las competencias concurrentes

25 Sobre ello, cfr. F. J. JIMÉNEZ de Cisneros CiD, «El nuevo régimen...», op. cit., pág. 117. 
sobre las dependencias demaniales que sirven de soporte a infraestructuras portuarias y viarias de titularidad autonómica ya ha sido realizada por quien tenía potestad para decidirla, las Cortes Generales, que han establecido en el art. 49 de la Ley un sistema que ha sido considerado constitucional en nuestra Sentencia 149/1991 (FJ 4.D.b.a). La ilegalidad del Reglamento en este punto no es inocua para el bloque de la constitucionalidad, porque afecta a una norma de la Ley en la que se ha definido un determinado equilibrio entre las competencias de las instituciones centrales y de las instituciones autonómicas del Estado. Por lo que es preciso declarar, sin más, la nulidad de este segundo apartado del art. $103 \mathrm{RC} . »$

Como consecuencia de esta Sentencia y en virtud del Real Decreto 1112/1992, la disposición contenida en el anterior art. 103.2 RC desaparece del texto del RC, de lo que resulta que la adscripción, como forma de utilización del dominio público por la Comunidad Autónoma para las competencias a las que está referida, es necesaria con independencia del tipo de gestión a que se someta la vía de transporte o el puerto.

\section{B. Supuestos excluidos de adscripción}

Únicamente los supuestos mencionados de construcción, modificación y ampliación de puertos y vías de transporte de competencia autonómica se encuentran sujetos $e x$ art. $49 \mathrm{LC}$ a adscripción, derivando así de la ratio del precepto la exclusión tanto de los casos en los que el fin de la utilización del demanio marítimo sea otro distinto a los relativos a puertos o vías de transporte, como de aquellos en los que, aun dirigida a aquellos fines, la utilización no suponga construcción, modificación o ampliación del puerto o de la vía de transporte.

a) Se excluyen por tanto de los supuestos sujetos a la técnica adscriptoria otros respecto de los cuales la Administración autonómica correspondiente, para ejercitar sus competencias, se vea necesitada de utilizar el dominio público marítimo-terrestre, v. gr., obras públicas de interés de la Comunidad Autónoma (art. 148.1.4 CE). En estos casos, toda vez que esta utilización del demanio marítimo ha de articularse mediante alguna de las técnicas previstas en la LC, habrá de solicitarse la oportuna autorización o concesión de la Administración estatal conforme a los arts. 51 y 64 LC. A nuestro juicio, sin embargo, la adscripción podía haberse extendido a otros supuestos, a esos otros fines de competencia autonómica, por un doble motivo.

En primer lugar porque en estos otros supuestos de utilización por la Comunidad Autónoma de demanio marítimo-terrestre, en la medida en que intervenga un particular en la actividad correspondiente, se producirán situaciones en 
LA ADSCRIPCIÓN DEL DOMINIO PÚBLICO MARITIMO-TERRESTRE..

las que sea necesario solicitar dobles títulos habilitantes de uso o explotación, de manera que tal particular puede encontrarse ante la obligación de solicitar autorización o concesión a la Administración del Estado así como la consiguiente autorización o concesión autonómica.

El principio de economía procedimental podría haberse tenido en cuenta en este punto, y utilizarse la técnica del informe de la Administración estatal como un acto perfecto en sí mismo, aunque inserto en el procedimiento de aprobación del proyecto de que se trate por la Administración autonómica. Esta vía parece más adecuada y «económica» que la prevista en el art. $150.1 \mathrm{RC}$, el cual, para paliar los posibles efectos perjudiciales para el administrado de una farragosa doble autorización o concesión, ha previsto que el particular presente las dos solicitudes ante el órgano competente de la Comunidad Autónoma, debiendo ésta recabar informe de la Administración del Estado en la tramitación del proyecto, informe que versará sobre la viabilidad de la ocupación, así como de las condiciones en las que ésta se otorgaría; posteriormente han de tener lugar los dos otorgamientos: primero el de la Administración estatal, y posteriormente el de la Administración autonómica. La adscripción se configura como una técnica bastante más ágil que el procedimiento descrito y, por este motivo, consideramos que hubiera sido deseable su extensión por el legislador a otros supuestos de competencia autonómica distintos a los comprendidos en el art. 49 LC, evitándose esta duplicidad de títulos que debe solicitar el particular.

En segundo lugar, y ciñiéndonos a los supuestos en los que, además del título habilitante autonómico, fuera necesaria concesión estatal, la vía de la doble concesión se nos antoja poco respetuosa con las competencias autonómicas si tenemos en cuenta la doctrina mantenida por el Tribunal Constitucional en la STC 149/1991 tantas veces citada. En esta Sentencia, como expusimos con anterioridad, se mantiene el carácter reglado del acto administrativo de adscripción, por cuanto considerar que pudiera tener carácter discrecional podría suponer un límite a las competencias autonómicas contrario al orden constitucional de competencias. En cuanto la concesión es un acto de carácter discrecional, tal carácter permite su otorgamiento en base a un juicio subjetivo de la Administración del Estado, con la consiguiente limitación de las competencias autonómicas. Se podía haber aprovechado en este sentido la adscripción para extenderla a esos otros supuestos, por cuanto aparece como técnica respetuosa con las competencias autonómicas, que va a permitir que, sobre un mismo espacio fisico, cada Administración ejercite sus potestades y competencias ${ }^{26}$.

26 En los Decretos de traspasos de servicios en materia de puertos, sin embargo, se daba esta doble función al informe estatal, pues se disponia en los mismos que la aprobación del proyecto conllevaba la adscripción a la Comunidad Autónoma de la nueva zona de servicios resultante, 0 , en su caso, la concesión administrativa de ocupación de dominio público. 
b) Quedan igualmente fuera del ámbito de aplicación de la adscripción las actuaciones autonómicas sobre puertos o vías de transportes existentes supuesto que éstos no vayan a ser modificados o ampliados, al no entrar dentro de los supuestos enumerados en el art. $49 \mathrm{LC}^{27}$.

En síntesis, podemos afirmar que la adscripción se ha concebido como técnica restringida a una serie de supuestos muy limitados, necesitándose de la concesión demanial para la utilización en los casos distintos a los previstos en la legislación de costas, del demanio marítimo-terrestre por las Comunidades Autónomas. Esta configuración restrictiva y limitada de una técnica que a nuestro juicio ofrece posibilidades infrautilizadas se extiende también al aspecto que a continuación se analiza, esto es, al de los sujetos que intervienen en la misma.

\section{SUJETOS}

Dos son los sujetos que intervienen en el mecanismo de adscripción de los terrenos necesarios para la construcción, ampliación o modificación de un puerto o una vía de transporte en el dominio público marítimo-terrestre: por una parte, la Administración del Estado, que adscribe y, por otra, la Administración autonómica, que se constituye en beneficiaria de la adscripción.

Será la Administración del Estado la que dicte el acto administrativo adscriptorio, siendo el órgano competente para emitir el informe relativo a la adscripción el Ministerio de Obras Públicas y Urbanismo en los términos del art. 203.4 RC, en la actualidad, el de Medio Ambiente ${ }^{28}$.

La Administración beneficiaria, es decir, la Administración que, al hilo de la tramitación del procedimiento ha de solicitar al Ministerio de Medio Ambiente la emisión del informe, puede serlo únicamente la Administración de una Comunidad Autónoma. Sin embargo, y dada la idoneidad de la técnica tanto para articular distintas competencias sobre un mismo espacio físico, como para hacer efectivo el principio de economía procedimental, se podían haber extendido también las posibilidades de su utilización a otras entidades territoriales, las entidades locales, que igualmente pueden verse necesitadas de la utilización de dominio público marítimo-terrestre para la gestión de sus competencias propias, establecidas en el art. $25 \mathrm{LBRL}^{29}$. En estos supuestos habrá de estarse al

\footnotetext{
27 No seria por tanto necesaria, $v$. gr., la renovación de la adscripción, una vez extinguida una concesion de explotación de un puerto, para conceder dicha explotación nuevamente.
}

Dada la última reestructuración de la Administración del Estado llevada a cabo en mayo de 1996.

En esta misma línea I. Lazcano Brotons, «La adscripción...», op. cit., pág. 207. 
régimen general de las autorizaciones y concesiones, siendo aplicables en este punto las objeciones expresadas en torno a la dilación de los. procedimientos administrativos.

\section{OBJETO}

El fundamento exclusivamente demanial de la adscripción conlleva importantes consecuencias, entre las cuales interesa destacar aquí que el objeto fisico de la misma viene constituido únicamente por los terrenos que formen parte del dominio público marítimo-terrestre ocupado por el puerto o la vía de transporte, según dispone el art. 103.3 RC ${ }^{30}$. De ahí que no sea objeto de adscripción la utilización de los terrenos colindantes a dicho demanio pero que sin embargo se afecten al puerto o a la vía de transporte. Ahora bien, en cualquier caso, y dado que las normas de protección del litoral establecidas en la LC no se limitan a lo que propiamente constituya dominio público marítimo-terrestre, la actuación autonómica sobre estos terrenos estará condicionada por el respeto a las servidumbres y demás limitaciones establecidas en el Título II LC ${ }^{31}$.

Son, por tanto, objeto de adscripción la ribera del mar y de las rías, compuesta por la zona marítimo-terrestre y las playas (art. $3 \mathrm{LC}$ ), así como otros bienes que, más allá de la enumeración del art. $132.2 \mathrm{CE}$, integran igualmente el dominio público marítimo-terrestre por mandato del art. $4 \mathrm{LC}$, como serían las accesiones a la ribera, los terrenos que se ganen al mar ${ }^{32}$, los terrenos invadidos

30 La anterior redacción de este precepto añadia como condicionante del otorgamiento de la adscripción la aprobación del deslinde de la zona de dominio público marítimo-terrestre afectada, disposición que, según la STC 1998/1991, incurria en extralimitación al imponer un requisito no previsto por la Ley.

31 De entre estas limitaciones, hemos de destacar aquí la prohibición de edificaciones destinadas a residencia o habitación en la zona de servidumbre de protección (art. 25 LC), prohibición no exenta de criticas basadas en la reducción de la rentabilidad en esta zona, a las que se puede responder que la servidumbre de protección ocupa únicamente los primeros 100 metros adyacentes al litoral, y ello simplemente supondría el retranqueo de estas edificaciones unos metros más atrás, lo cual tampoco parece que pudiera reducir en exceso la rentabilidad de los terrenos en cuestión.

32 El art. 9 LC pone fin a la posibilidad de adquirir la propiedad privada de estos terrenos que venía siendo permitida tanto por la legislación de puertos como de puertos deportivos en favor de los particulares y de las Corporaciones Locales (vid arts. 57 de la Ley de Puertos de 1880, 54 de la Ley de Puertos de 1928, 101 del Reglamento de Puertos de 1928, 5.3 Ley de Costas de 1969, 18 LPD y 25 RPD), admisión que, sin embargo, contó con duras críticas doctrinales (pueden verse en este sentido los trabajos de J. LEGU. NA Villa, «Propiedad privada y servidumbre de uso público en las riberas del man», RAP n. ${ }^{\circ} 65,1979$, págs. 63 y ss, y "La defensa del uso público de la zona marítimo-terrestre», $R E D A$ n. ${ }^{\circ}$ 2, 1974, págs. 185 y ss, inter alia. La disposición transitoria segunda LC ha respetado, no obstante, las situaciones de los terrenos ganados por la propiedad privada con anterioridad a la entrada en vigor de la LC, siempre y cuando su adquisición hubiere tenido lugar en virtud de cláusula concesional expresa. Ha de señalarse que los paseos maritimos construidos con terrenos ganados al mar participan de esta condición, y, en 
por el mar ${ }^{33}$, los acantilados, los terrenos de dominio público que perdieran sus características naturales, los islotes, los terrenos incorporados por los concesionarios, los terrenos colindantes adquiridos para su incorporación al dominio público marítimo-terrestre y las obras e instalaciones construidas por el Estado en dicho dominio y las de iluminación de costas y señalización marítima.

\section{LA FORMA DE LA ADSCRIPCIÓN}

La adscripción del dominio público marítimo-terrestre ha de llevarse a cabo a través del procedimiento previsto en el art. $105 \mathrm{RC}$ y exteriorizarse mediante acta, según dispone el apartado tercero del art. 49 LC.

El procedimiento de adscripción se incardina dentro del procedimiento de aprobación del proyecto del puertoo de la vía de transporte, debiendo iniciarse mediante la remisión, por parte de la Comunidad Autónoma, de dicho proyecto al Ministerio de Medio Ambiente. Este Departamento ha de emitir informe, de carácter vinculante, en el plazo de dos meses. La LC, sin embargo, no preveía el supuesto de que transcurridos los dos meses la Administración estatal no se hubiera pronunciado, cuestión que ha sido no obstante resuelta por la STC 149/1991, la cual obliga a entender el silencio de la Administración estatal en sentido positivo, al considerar que lo contrario supondría condicionar el ejercicio de sus competencias por las Comunidades Autónomas ${ }^{34}$.

Ya sea expresa o presunta la forma en que la Administración estatal muestre su conformidad con la utilización del dominio público marítimo-terrestre por la Comunidad Autónoma, el acto resolutorio del procedimiento, es decir, el acto de aprobación definitiva del proyecto por la Comunidad Autónoma, tiene un doble contenido o efecto, pues por una parte aprueba el proyecto de puerto o vía de transporte y, por otra, como se establece en el art. 49.3 LC, conlleva la

otro caso, habrán de ser peatonales y contruidos preferentemente fuera de la ribera del mar, ex art 44.5 LC.

33 Dentro de este supuesto han de incluirse los terrenos inundados por la construcción de marinas, definidas por el art. $436 \mathrm{RC}$ como las urbanizaciones marítimo-terrestres que den origen a la invasión de terrenos por el mar o por las aguas de los rios, hasta donde se haga sensible el efecto de las mareas. El dominio público marítimo-terrestre lo constituye el terreno inundado, exclusivamente; la zona de servicio de las marinas, por tanto, no se integra en dicho demanio.

34 Con respecto al plazo de emisión del informe ha de destacarse el contenido de la LC que en este punto, merece una valoración positiva, al ser más progresiva que los Decretos de traspasos de servicios en materia de puertos, los cuales en su mayoria establecian un plazo de seis meses para que la Administración estatal lo evacuase, salvo en los casos de Andalucia y Baleares, en los que se establecia un plazo de tres meses. Ahora bien, sí estaba previsto en los citados Decretos, el supuesto de no emisión, en cuyo caso habia de entenderse favorable. 
LA ADSCRIPCIÓN DEL DOMINIO PÚBLICO MARITTMO-TERRESTRE...

adscripción del dominio público marítimo-terrestre necesario para llevar a cabo tal proyecto ${ }^{35}$.

Un requisito formal más, atinente a la forma de exteriorización del acto administrativo, ha de llevarse a cabo para cumplimentar el mecanismo adscriptorio, requisito de cuya realización va a depender el momento a partir del cual puedan comenzar las obras y que consiste en la formalización de la misma mediante acta que habrá de suscribirse, junto con el plano de adscripción, por representantes de ambas Administraciones (art. 49.3 LC in fine, en relación con el $105 \mathrm{RC})$.

El sentido del acta de ocupación va a ser el de proporcionar la necesaria constancia del momento en el que se produce la subrogación de la Comunidad Autónoma en el ejercicio de las potestades demaniales, entendiéndose efectuada la toma de posesión y ocupación de los bienes en el momento en el que se suscribe por los representantes de las Administraciones implicadas ${ }^{36}$. Será a partir de este momento de firma del acta cuando la adscripción comience a producir todos los efectos que a continuación se analizan ${ }^{37}$.

\section{EFECTOS}

Producida la adscripción del dominio público marítimo-terrestre necesario para construir, ampliar o modificar un puerto o una vía de transporte autonómicos, la Administración autonómica se subroga en el ejercicio de las potestades de uso y aprovechamiento y la Administración del Estado conserva las potestades de defensa y conservación y mantiene la titularidad de todas ellas.

a) Entre las potestades en cuyo ejercicio se subroga la Comunidad Autónoma se encuentra la de otorgamiento de los títulos habilitantes para la utilización y gestión del dominio público adscrito, por lo que desde que se produzca la adscripción, la Administración competente para otorgar las auto-

\footnotetext{
35 El art. $105 \mathrm{RC}$ añade a este respecto la obligación de la Comunidad Autónoma de comunicar la aprobación del proyecto a la Administración del Estado.

36 Algo similar a la traditio ficta, art. $1462 \mathrm{Cc}$.

37 La previsión del acta ha sido objeto de duras críticas basadas fundamentalmente en la duplicidad de actos y la consecuente ralentización del procedimiento. En este sentido J. BALzA AGULLER, «Reflexión de carácter constitucional...», op. cit., pág. 77 y M. J. MONTORO CHINER, «La Ley de Costas. ¿Un proyecto viable?» $R E D A$ n. 58 (1988), pág. 205. Creemos sin embargo que el verdadero sentido del acta es el que hemos indicado y, entendida así, más que nada va a suponer garantías, pues permite dejar constancia del momento concreto en el que puede comenzar a surtir y desplegar todos sus efectos la adscripción.
} 
rizaciones y concesiones que habiliten el uso de dicho dominio público por los particulares será la autonómića siempre que la finalidad perseguida con ese uso sea acorde a las previstas en el art. $49 \mathrm{LC}$ (puertos y vías de transportes autonómicas).

b) La Administración del Estado, no obstante, retiene las restantes potestades a ejercitar sobre dicho demanio, concretamente y como convinimos con anterioridad, las potestades de defensa, razón por la cual a esta Administración corresponderá el ejercicio de las potestades de deslinde, recuperación de oficio, potestad sancionadora, etc., reguladas todas ellas en la legislación de costas.

c) Como expresamente dispone el art. 49 LC, la porción de terreno adscrita conserva su calificación jurídica, la de dominio público marítimoterrestre y, por tanto, la titularidad estatal. En virtud de esta titularidad estatal sobre el dominio público adscrito, el ejercicio de las potestades de uso y aprovechamiento por las Comunidades Autónomas se somete por el art. $49.1 \mathrm{LC} \mathrm{a}$ una serie de límites o condicionantes. En primer término dicho ejercicio habrá de tener lugar, en cualquier caso, de forma adecuada a su finalidad (la construcción, modificación y ampliación de puertos y vías de transporte de su competencia); en segundo lugar, la utilización y gestión del demanio adscrito habrá de llevarse a cabo con sujeción a las disposiciones pertinentes ${ }^{38}$.

d) Desde esta perspectiva y en el supuesto de gestión por los particulares, el título habilitante autonómico llevará implícito el título demanial ${ }^{39}$, lo que supone que si bien la Comunidad Autónoma concentra el ejercicio de las potestades de uso y aprovechamiento, dichas potestades van a estar sujetas a las limitaciones que a continuación se señalan y que se derivan de la utilización que de dominio público maritimo-terrestre tiene lugar.

e) Las Comunidades Autónomas, en virtud de las citadas potestades de uso y aprovechamiento y una vez adscrito el dominio público marítimo-terrestre, pueden habilitar el uso del litoral, pero ello podrá ser así siempre y cuando ese uso sea compatible con la legislación de costas. La disposición transitoria 15.8) RC faculta inclu-

38 Esta referencia a las «disposiciones pertinentes» ha de interpretarse, como ha puesto de relieve el Tribunal Constitucional (STC 149/1991), en el sentido de que tal inciso no habilita a la Administración del Estado a regular la gestión o explotación de los puertos o vias de transporte realizados por la Comunidad Autónoma, pues lo contrario supondria interferir la exclusiva competencia de ésta.

39 Especial mención merece la Ley de Patrimonio de Andaluciá, cuyo art. 33 establece que se entenderá implícitamente otorgada la concesión para uso privativo de aquellos bienes de dominio público pertenecientes a la Comunidad Autónoma necesarios para la prestación del dominio público. El art. 37.2 de la Ley de Patrimonio de Murcia dispone también que el título demanial se entiende implicito en la concesión de servicios. 
so a las Comunidades Autónomas a revocar, previa indemnización, las concesiones de su competencia si resultan incompatibles con los criterios de ocupación del dominio público establecidos en la LC.

En todo caso, son incompatibles con dichos criterios el mantenimiento de concesiones a perpetuidad, por tiempo indefinido, sin plazo limitado o por plazo superior a treinta años, a contar desde la entrada en vigor de la LC, siempre que no hayan superado o superen el plazo máximo de noventa y nueve años. De esta forma, el plazo de las concesiones otorgadas por las Comunidades Autónomas para la gestión del demanio adscrito, como establece el art. 49.1 LC in fine, no podrá exceder de treinta años ${ }^{40}$.

La constitucionalidad de esta limitación ha sido confirmada por la STC 149/1991, Sentencia que considera que el precepto se ciñe a recordar la regla general relativa al plazo máximo de las concesiones establecida en el art. 66.2 LC, cuyo contenido refleja una determinación legislativa que corresponde a la competencia exclusiva del Estado para regular el régimen jurídico del dominio público marítimo-terrestre. A nuestro juicio, el fundamento último de esta limitación vendría constituido por la propia definición de adscripción que aquí se ha proporcionado, ya que el legislador, respecto de las potestades cuyo ejercicio traslada a la Comunidad Autónoma, puede conformar y establecer el contenido y las condiciones de ejercicio de dichas potestades, entre ellas, el plazo máximo de los títulos que habiliten la utilización del dominio público sobre el que se podrán ejercitar $^{41}$.

\footnotetext{
40 Los plazos que en las distintas leyes de patrimonio autonómicas se prevén para las concesiones administrativas, en muchos casos, se van a ver limitados por esta disposición de la Ley de Costas. En este sentido, la mayoria de los plazos concesionales se situan en treinta (arts. 28, 69.3 y 69 de las Leyes catalana, canaria y balear, respectivamente) y cincuenta años (arts. 57.2 y 3 y 73 de la Ley del Pais Vasco; art. 60.2 de la Ley cántabra, y art. 90 de la andaluza), entre estos últimos se encuentra el caso de Galicia, en el que incluso se permite la prórroga por mutuo acuerdo (art. 54.1) La Comunidad Autónoma de Murcia es la que cuenta con un plazo mayor establecido, la concesión podrá tener un plazo máximo de noventa y nueve años (art. 38 de la Ley de Patrimonio de Murcia; la legislación anterior, la Ley de 31 de julio de 1985, establecía, sin embargo, un plazo de treinta años).
}

41 Sería también posible la solución contraria, es decir, queda también a la libre configuración del legislador optar por no establecer tal límite, y dejar a la Comunidad Autónoma correspondiente la facultad de establecer el plazo máximo de las concesiones que otorgue sobre el demanio adscrito. Por otra parte, el plazo podria ser también menor. De la lectura del art. $66 \mathrm{LC}$, se deduce que el plazo puede ser reducido por la Administración autonómica, como mantenía la Jurisprudencia que en STS de 21 de febrero de 1976 consideró ajustada a Derecho la reducción a 30 años de una concesión, cuyo plazo, según el art. $126 \mathrm{LPE}$, aplicable al supuesto, no podia superar los noventa y nueve años, pues «la adopción de dicho plazo fue fijado por la Administración a la vista de los precedentes y, fundamentalmente, de los intereses públicos afectos por dicha concesión», añadiéndose en la citada Sentencia que uen la concesión de bienes demaniales ese interés particular, se actúa con un criterio restrictivo", no resultando por ello afectado el margen de discrecionalidad con que la Administración se desenvuelve en estos supuestos por la reducción del plazo. 
2) Por otra parte, la autorización o concesión autonómica devenga canon de ocupación en favor de la Administración del Estado con independencia del canon que la Comunidad Autónoma pudiera exigir (art. 104.3 RC) ${ }^{42}$. La única excepción a esta regla general del doble canon se producirá en los supuestos de autorizaciones o concesiones que las Comunidades Autónomas otorguen en los puertos e instalaciones portuarias que fueron transferidos y expresamente se relacionaban en los Decretos de traspasos de servicios en materia de puertos (disposición adicional tercera RC, introducida por el Real Decreto 1112/1992), en cuyo caso no es exigible el canon de ocupación a favor de la Administración del Estado ${ }^{43}$.

El art. 104.3 RC, en su primera redacción, establecía sin embargo que las autorizaciones o concesiones autonómicas en dominio público adscrito no devengarían canon a favor del Estado; ello venía motivado porque dichas autori-

42 Respecto al régimen de estas prestaciones patrimoniales ha de tenerse en cuenta la doctrina que en relación a las mismas ha introducido recientemente en la STC 185/1995, de 14 de diciembre (Suplemento BOE n. ${ }^{\circ} 11$, de 12 de enero de 1996), que declara la inconstitucionalidad de parte del art. 24 de la Ley 8/1989, de 13 de abril, de Tasas y Precios Públicos - vid., al respecto M. Zambonino Pulrro, «Exigencia de reserva de ley para el establecimiento de los ingresos percibidos por la Administración por la utilización del dominio público y por la prestación de determinados servicios públicos (STC 185/1995, de 14 de diciembre)", Administración de Andalucia n. ${ }^{\circ} 28$ (1996), págs. 87 a 105-, precepto que enumeraba los supuestos sujetos al pago de un precio público, entre los que se encontraba la utilización especial o privativa del dominio público. Esta declaración de inconstitucionalidad afecta, entre otros, justamente a este supuesto de utilización del dominio público. Ahora bien, en la medida en que la declaración de inconstitucionalidad se debe al incumplimiento por la LTPP del principio de reserva de ley que consagra el art. 31.3 CE en relación a las prestaciones patrimoniales de carácter público, puede afirmarse que el canon de ocupación demanial podrá seguir calificándose de precio público siempre y cuando su determinación tenga lugar en una ley formal. De cualquier forma, la STC 185/1995 obliga a una revisión, igualmente, de la legislación autonómica de tasas y precios públicos, legislación que, salvo en el caso de la Comunidad Autónoma andaluza, califica también como precio público la prestación que se satisfaga por utilizar el dominio público (arts. 23 de la Ley 33/1991, de 24 de diciembre, de Tasas y Precios Públicos de la Generalidad de Cataluña; 142 de la Ley 3/1990, de 18 de septiembre, de Tasas y Precios Públicos de la Administración de la Comunidad Autónoma del País Vasco; 9 de la Ley 13/1991, de 9 de diciembre, de tasas, precios y exacciones reguladoras de la Comunidad Autónoma de Galicia; 143 de la Ley 5/1990, de 22 de febrero, de Tasas y Precios Públicos de la Comunidad Autónoma de Canarias; y 1 de la Ley $2 / 1990$, de 19 de diciembre, que modifica parcialmente la Ley 5/1988, de 22 de julio, de Tasas y Exacciones Parafiscales del Principado de Asturias; los ingresos percibidos por la utilización del dominio público de la Comunidad Autónoma de Andalucía son calificados como tasas por el art. 4 de la Ley 4/1988, de Tasas y Precios Públicos de la Comunidad Autónoma).

43 El fundamento de esta excepción a la regla general parece estar en la idea de favorecer la explotación de los puertos ya existentes, en un intento por reducir, al suponer un mayor gravamen para el particular, la creación de nuevos puertos, y con ello el impacto que éstos pueden causar en el litoral, en aras de su protección. Consecuentemente con ello, el segundo párrafo del art. 14.4 de la Ley de Puertos y de la Marina Mercante establece que ulas concesiones o autorizaciones que las Comunidades Autónomas otorguen en los puertos $\mathrm{e}$ instalaciones portuarias estatales que les fueran transferidos y figuran expresamente relacionados en los correspondientes Reales Decretos de traspasos en materia de puertos, no devengarán el canon de ocupación a que se refiere el párrafo anterions. 
LA ADSCRIPCIÓN DEL DOMINO PÚBLICO MARITIMO-TERRESTRE...

zaciones y concesiones ya estaban sujetas a canon estatal, por cuanto el art. 103.2 $\mathrm{RC}$, en su versión original, establecía la necesidad de doble título habilitante, estatal y autonómico, y la primera, según el art. 84.1 LC, está sujeta a canon estatal, con lo cual resultaba la posibilidad de imposición de un doble canon: uno, en favor de la Administración estatal derivado de la concesión o autorización otorgada por ésta y, otro, inherente a la concesión o autorización autonómica en su caso.

Sin embargo, la anulación del precepto por la STC 198/1991, de 17 de octubre, con la consiguiente supresión de la exigencia de doble título habilitante, y la afirmación de que el único mecanismo para la construcción, ampliación o modificación de puertos o vías de transporte es la adscripción, supondrían la imposibilidad de que la Administración del Estado percibiese canon alguno en aquellos supuestos ${ }^{44}$. Es ésta la razón de que el art. 104.3 RC, en su redacción actual, exija el canon estatal derivado de una concesión o autorización autonómica, recurriéndose así, vía reglamentaria, a la imposición al particular de la obligación de abonar un segundo canon, además del correspondiente a la Administración autonómica, en favor del Estado.

Ha de resaltarse en este punto que, con independencia de la anulación por el Tribunal Constitucional de la necesidad de doble título, la STC 198/1991 no hizo objeción alguna (más bien al contrario, justificó) a la posibilidad de exigir un doble canon al titular de una concesión o autorización autonómica derivada de la anterior redacción del $\mathrm{RC}^{45}$, doctrina que justificaría igualmente la actual exigencia de un doble canon (aunque esta vez derivado de la misma concesión) ex art. $104 \mathrm{RC}$.

\section{LA REVERSIÓN DE LOS BIENES ADSCRITOS}

Aunque no se encuentra sometido a plazo alguno, el ejercicio de las potestades de uso y aprovechamiento sobre los bienes adscritos por las Comunidades Autónomas encuentra su término en la producción de determinados supuestos que justifican

\footnotetext{
44 El razonamiento que lleva al Tribunal Constitucional a anular la doble concesión parte de la consideración de que se produjo una extralimitación por parte del art 103.2 RC, ya que urestringe drásticamente el margen que el art. 49 LC deja para la actuación de las Comunidades Autónomas en ejercicio de sus competencias sobre vías de transporte y, sobre todo, sobre puertos».

45 La citada Sentencia consideraba que del art. 84.1 LC no se deriva una doble imposición, al tratarse de distintas circunstancias que dan lugar a otros tantos hechos imponibles, determinantes a su vez de figuras tributarias diferentes. Así pues, y para el Tribunal Constitucional, la previsión de que el canon por ocupación del demanio costero puede coexistir con tasas u otros tributos exigibles por la Administración otorgante de la concesión o autorización no suscita en sí cuestión alguna.
} 
la obligación de éstas de proceder a la devolución de dichos bienes a la Administración del Estado. Ésta es básicamente la configuración que la LC ofrece de la reversión del dominio público marítimo-terrestre adscrito, técnica cuya utilización queda condicionada a que se produzca alguna de las circunstancias enumeradas en el art. $50 \mathrm{LC}$ y que se somete a un riguroso procedimiento cuya tramitación va a ser distinta según cual sea el supuesto que la justifique.

\section{A. Supuestos que dan lugar a la reversión}

1) El primero de los supuestos enumerados en el art. $50 \mathrm{LC}$ consiste en la no utilización del bien para el cumplimiento de los fines a los que se adscribiera, en cuyo caso la reversión se justifica por la propia configuración que la legislación de costas otorga a la adscripción, la cual, como sabemos queda limitada a la construcción, ampliación o modificación de puertos o vías de transporte de competencia autonómica. La reversión habrá de tener lugar, pues, únicamente en los casos en los que deje de utilizarse el demanio marítimo-terrestre adscrito a alguno de estos fines.

Surge, sin embargo, una cuestión no resuelta por la Ley, cual es la de la procedencia de la reversión en el supuesto de cambio de destino del puerto o de la vía de transporte, si este nuevo destino es igualmente de competencia autonómica (v. gr., puerto deportivo que pasa a utilizarse para fines pesqueros exclusivamente, o vía que de carretera pasa a constituir vía férrea o viceversa). Cabría considerar aquí dos posibilidades: en primer lugar, podría mantenerse que en estos casos habría de tener lugar la reversión de los bienes adscritos, para proceder, posteriormente, a una nueva adscripción; podría considerarse también la innecesariedad de la reversión, opción ésta que parece más acorde con el principio de economía procedimental ${ }^{46}$, y que podría tener lugar sin perjuicio de una posterior y obligatoria renovación de la adscripción durante el desarrollo del procedimiento de aprobación del proyecto por la Comunidad Autónoma.

2) La reversión de los bienes adscritos a una Comunidad Autónoma para que ejercite sus competencias en materia de puertos y vias de transporte sobre el dominio público marítimo-terrestre tendrá lugar igualmente cuando dichos bienes sean necesarios para la actividad económica o el interés general. La justificación de estos supuestos la proporciona de forma expresa el propio art. 50 LC, precepto que se remite a los arts. 131 y 149 CE. A pesar de esta remisión a

\footnotetext{
46 Piénsese que si se considera la necesidad de que los bienes reviertan, habrán de seguirse dos procedimientos: en primer lugar, el de reversión que más adelante se expondrá, para posteriormente adscribir, al hilo de la aprobación del proyecto por la Comunidad Autónoma, los terrenos que acaban de devolverse, adscripción que, dado su carácter reglado, necesariamente habrá de ser otorgada si se dan los elementos que la LC establece y se han estudiado.
} 
LA ADSCRIPCIÓN DEL. DOMINIO PÚBLICO MARITLMO-TERRESTRE...

preceptos constitucionales, hemos de convenir que la ambiguledad de los términos va a obligar a una interpretación casuística de los mismos a posteriori, interpretación que habrá de llevarse a cabo por la Administración del Estado, dejando a ésta un amplio margen de decisión respecto a materias que son competencia de las Comunidades Autónomas ${ }^{47}$. En cualquier caso, serán los Tribunales los que en último extremo tengan que decidir si en tal interpretación ha existido una extralimitación de forma que se hubieran invadido las competencias autonómicas.

\section{B. Procedimientos de reversión}

El procedimiento previsto para la reversión de los bienes adscritos a una Comunidad Autónoma se encuentra regulado en el art. $107 \mathrm{RC}$, y consta de unas fases comunes para los dos supuestos que la justifican (iniciación y terminación) difiriendo el desarrollo del mismo según se trate de que la reversión se fundamente en el incumplimiento de los fines a los que los bienes se adscribieron o en su necesidad para la actividad económica o el interés general.

a) En ambos casos el procedimiento puede iniciarse por cualquiera de las Administraciones que entran en relación a través del instituto adscriptorio. La reversión puede iniciarse así por la Administración del Estado, concretamente por el Ministerio de Medio Ambiente, en cuyo caso habrá de comunicarse esta circunstancia a la Comunidad Autónoma correspondiente. Si es la Administración autonómica la que insta la reversión, la solicitud deberá dirigirse al mismo Departamento, el cual la tramitará conforme al procedimiento que corresponda.

b) El desarrollo del procedimiento varía según el supuesto de que se trate.

En el caso de incumplimiento de los fines a los que se adscribieron los bienes, el Ministerio de Medio Ambiente habrá de solicitar informe a la Comunidad Autónoma, que deberá emitirse en el plazo de un mes, y si es favorable, se propondrá la reversión al Consejo de Ministros. Si el informe fuera desfavorable, ha de abrirse un período de consulta entre ambas Administraciones, para resolver, de común acuerdo, las diferencias ${ }^{48}$.

47 Este extremo es el que justamente ha provocado las críticas doctrinales en cuanto a la reversión del demanio adscrito. En este sentido J. BALZA AGuILERA, «Reflexión constitucional...», op. cit., págs. 78 y 79 , quien señala el hecho de que precisamente tanto los puertos como las vias de transporte son necesarios tanto para la actividad económica como para el interés general, pudiendo suponer ésta una vía para recortar las competencias autonómicas.

48 Esta regulación es la contenida en la última redacción del $\mathrm{RC}$. La anterior regulación únicamente preveia un trámite de audiencia en favor de la Comunidad Autónoma, conservando, la Administración del Estado, la facultad de decidir. Sin embargo, el Tribunal Constitucional, en su STC 198/1991 consideró que, dando 
En el supuesto de que los terrenos adscritos sean necesarios para la actividad económica o el interés general, y en la medida en que se trata de materias de competencia del Estado, es a éste al que corresponde decidir la reversión, otorgándose a la Comunidad Autónoma un plazo de un mes para que formule las alegaciones que estime pertinentes, alegaciones que habrán de incorporarse a la propuesta de resolución que se eleva al Consejo de Ministros.

c) La terminación del procedimiento tiene lugar por acuerdo del Consejo de Ministros; no obstante, resta por considerar aún un requisito relativo a la forma de exteriorizar el acuerdo de reversión consistente en la necesaria formalización del mismo mediante acta suscrita por los representantes de ambas Administraciones, cuyo sentido es básicamente el mismo que el que hemos atribuido al acta de adscripción: hacer constar el momento preciso en el que la Administración del Estado toma posesión de los bienes que revierten.

\section{Efectos}

Los efectos de la reversión van a ser justamente los contrarios a los que se han analizado con respecto a la adscripción y que podemos sintetizar del siguiente modo.

Por una parte, la Comunidad Autónoma cesará en el ejercicio de las potestades de uso y aprovechamiento, por lo que vuelven a concentrarse en la Administración estatal la titularidad y el ejercicio de todas las potestades demaniales, tanto de uso y aprovechamiento como de defensa y conservación.

A lo anterior ha de añadirse que, dada la configuración que de la reversión se hace en la legislación de costas, el cambio de destino del bien es un efecto necesario e ineludible de la misma. $\mathrm{El}$ art. $50 \mathrm{LC}$ establece al respecto que a los

audiencia a las Comunidades Autónomas, no quedaban salvaguardadas las competencias de las dichas Comunidades, ya que estos fines son, por definición, de competencia autonómica, y por tanto, sólo la Comunidad Autónoma ejerce la gestión o, en su caso, la inspección y control de los correspondientes servicios, de manera que su criterio acerca del funcionamiento de éstos y, en consecuencia, sobre la utilización de los terrenos para los fines a que fueron adscritos tiene una especial relevancia. De esta manera, en la redacción final del precepto, se ha dado la misma importancia tanto al criterio de la Comunidad Autónoma como al de la Administración estatal («de común acuerdo»), lo que a la vista de la STC 198/1991, que otorgaba un carácter relevante al criterio autonómico, puede ser de dudosa constitucionalidad. En cualquier caso, y dada la interpretación del Tribunal Constitucional, si dicho acuerdo no se produce (supuesto no contemplado en el RC), no procederá la reversión de los terrenos adscritos. Por su parte, los Decretos de traspasos de servicios en materia de puertos dejaban a la Comunidad Autónoma la resolución acerca del hecho de que los bienes hubieran dejado de ser necesarios para el cumplimiento de los fines portuarios, solución ésta que nos parece más acorde con el bloque de la constitucionalidad, utilizando el mismo razonamiento que se usa para el segundo de los supuestos en favor del Estado y que a continuación examinamos. 
bienes que reviertan a la Administración del Estado se les dará el destino que en cada caso resulte procedente. Por su parte, el RC no especifica nada más, sin embargo, es posible concluir que el destino que haya de darse a dichos bienes vendrá condicionado por los supuestos que justifican la reversión.

En este sentido, si la reversión viene fundamentada en el incumplimiento de los fines que dieron lugar a la adscripción, en ningún caso el nuevo destino podrá ser alguno de los fines enumerados en el art. 49 LC (construcción, ampliación o modificación de puertos o vías de transporte de competencia autonómica) por la sencilla razón de que la Administración del Estado no cuenta con competencia para ello. Por otra parte, si la reversión vino motivada por la necesidad de los bienes para la actividad económica o el interés general el nuevo destino que habrá de darles la Administración estatal habrá de estar vinculado a estas finalidades, pues en caso contrario se produciria una conculcación de las competencias de las Comunidades Autónomas, que se hubieran visto burladas por la reversión injustificadamente realizada.

\section{CONCLUSIONES}

No queremos finalizar este trabajo sin antes ofrecer al lector, a modo de conclusiones, una serie de ideas finales sintetizadoras de todo lo que con anterioridad se ha expresado, y que pueden resumir el contenido del mismo.

1. La adscripción es una técnica concebida en la legislación de costas como mecanismo para facilitar el ejercicio de las Comunidades Autónomas de determinadas competencias en el dominio público marítimo-terrestre mediante la cual la Administración del Estado dicta un acto administrativo reglado por el que se cede el mero ejercicio de ciertas potestades demaniales a otra entidad territorial (y no su titularidad), a la Administración autonómica, la cual se subroga en el ejercicio de dichas potestades en virtud de un título competencial específico (puertos y vías de transporte). La cesión va a tener lugar respecto de las potestades de uso y aprovechamiento, de utilización, del dominio público; quedan pues para la Administración estatal las potestades de defensa y conservación, potestades éstas que, en cualquier caso, podrán, y deberán, ser ejercitadas en el demanio adscrito.

2. El carácter de acto reglado de la adscripción no se desdice por el hecho de que la forma que reviste sea la de un informe vinculante que, en el procedimiento de aprobación del proyecto de modificación, ampliación o construcción del puerto o de la vía de transporte, ha de emitir la Administración del Estado, puesto que lo que este procedimiento supone es un acto administrativo complejo en el que se integran dos declaraciones de voluntad perfectas en sí mismas 
provenientes de distintas Administraciones Públicas y en el que el sentido del acta de ocupación a suscribir por ambas radica en hacer constar el momento en el que se produce la efectiva subrogación por la Comunidad Autónoma en el ejercicio de las potestades demaniales.

3. En ningún caso la cesión de potestades demaniales que la adscripción comporta va a suponer el cambio de calificación jurídica del dominio público marítimo-terrestre adscrito, dominio que continuá siendo de titularidad estatal. Este carácter va a determinar que, sin perjuicio de que las potestades de utilización hayan de ejercitarse por la Administración autonómica, en el régimen de uso de los terrenos adscritos hayan de tenerse presente algunas determinaciones de la legislación de costas, tales como la limitación del plazo concesional a treinta años y la obligación de satisfacer canon de ocupación en favor de la Administración del Estado con independencia del canon que la Comunidad Autónoma pudiera exigir.

4. La finalidad con la que la técnica adscriptoria ha sido concebida queda limitada a poner a disposición el demanio marítimo-terrestre necesario para que las Comunidades Autónomas puedan modificar, ampliar o construir puertos y vías de transporte de su competencia. Esta restricción con la que se configura la adscripción resulta, a nuestro juicio, excesiva, pudiendo haberse considerado como mecanismo para facilitar el ejercicio de otras competencias de las Comunidades Autónomas, y no únicamente de éstas, sino también de los municipios. Limitarla a aquellos supuestos supone que, en cuanto entren en juego otros títulos competenciales autonómicos, habrá de obtenerse concesión demanial para poder ejercitarlos, lo cual nos parece puede vulnerar, por una parte, el sistema constitucional de competencias en la medida en que la concesión conlleva una decisión discrecional por parte de la Administración estatal y, por otro, y en cuanto se trate de utilización por los particulares, trasladar a éstos la carga de una doble concesión $\longrightarrow$ de una autorización a la que habría de sumarse la concesión estatal-.

5. El carácter restrictivo de la adscripción ha de mantenerse, no obstante, respecto al objeto de la misma y a su contenido, debiendo, por una parte, entenderse únicamente referida a la parte del demanio marítimo-terrestre que el puerto o la vía de transporte ocupen, pero no a los terrenos adyacentes a dicho espacio y, por otra, dirigirse a preservar la integridad fisica y jurídica de dicho demanio, agotándose en este punto la intervención estatal.

6. El ejercicio de las potestades de uso y aprovechamiento sobre los bienes adscritos por las Comunidades Autónomas encuentra su término en la producción de determinados supuestos que justifican la reversión de dichos bienes a la Administración del Estado. La reversión queda no obstante condicionada a 
LA ADSCRIPCIÓN DEL DOMINIO PÚBLICO MARITIMO-TERRESTRE..

que los bienes dejen de utilizarse para los fines a los que se adscribieron o sean necesarios para la actividad económica o el interés general. Ha de matizarse en este sentido que, en el primero de los supuestos, la reversión se haría innecesaria si el nuevo destino fuera igualmente de competencia autonómica, $y$ en el segundo, que la interpretación que se lleve a cabo de la necesidad para la actividad económica o el interés general, a pesar de ser llevada a cabo por el Estado, en ningún caso podrá suponer invasión de las competencias autonómicas.

En síntesis, la normativa de costas ha logrado cerrar y apuntillar el mecanismo de la adscripción de manera completa y, a nuestro modo de ver, satisfactoria, de forma que resulta una técnica especialmente idónea para alcanzar el objetivo con el que se concibe: facilitar el ejercicio de competencias autonómicas. Precisamente esta idoneidad nos hace considerar el carácter excesivamente restrictivo con la que el legislador la ha configurado. 
